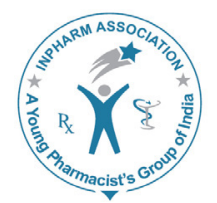

\title{
Phenytoin Toxicity: A Case Report
}

\author{
Vineetha Bharathan Menon', Justin Kurian'1, Krishna Undela', Madhan \\ Ramesh $^{1 *}$ and Hathur Basavana Gowdappa ${ }^{2}$
}

\author{
${ }^{1}$ Department of Clinical Pharmacy, JSS Medical College \& Hospital, JSS University, Mysore - 570 004, \\ Karnataka, India \\ ${ }^{2}$ Department of General Medicine, JSS Medical College \& Hospital, JSS University, Mysore- 570 004, \\ Karnataka, India
}

\begin{abstract}
Background: Phenytoin is a commonly used sedative antiepileptic medication in many countries. It is used against tonic-clonic and complex partial seizures. Phenytoin is reported to cause a range of deleterious and erratic side effects at therapeutic and toxic doses. Case report: An eighteen year old female presented with ataxia, nystagmus, gingival hypertrophy, nodular skin lesions and hirsutism while she was on treatment with oral phenytoin at $200 \mathrm{mg}$ once daily since the past five years for seizures. Based on the presenting signs and symptoms, her condition was diagnosed as phenytoin induced toxicity. The symptoms improved significantly after the offending drug was withdrawn. Alternatively she was started on oral carbamazepine. Naranjo and WHO causality assessment was done, indicating a probable relationship between the patient's symptoms and her use of phenytoin. Conclusion: This case report and review highlights the adverse drug reactions of phenytoin and the need of regular monitoring in patients on long term therapy.
\end{abstract}

Key words: Ataxia, Gingival hypertrophy, Hirsutism, Nodular skin lesions, Nystagmus Phenytoin toxicity.

\section{INTRODUCTION}

Epilepsy is a common neurological disorder. The main goal of treatment is to achieve seizure control without adverse effects. ${ }^{1}$ Phenytoin (5,5-diphenylhydantoin) is one of the most effective ${ }^{2}$ and widely prescribed ${ }^{3,4}$ drug for the treatment of epilepsy due to its low cost and easy availability. ${ }^{5}$ It was introduced as an antiepileptic drug in 1938. Phenytoin is commonly used to treat all types

\begin{tabular}{|c|c|}
\hline \multicolumn{2}{|c|}{ Access this article online } \\
\hline Journal Sponsor & \multirow[b]{2}{*}{$\begin{array}{l}\text { Website: } \\
\text { www.jyoungpharm.org }\end{array}$} \\
\hline \multirow{2}{*}{ www.phcog net } & \\
\hline & $\begin{array}{l}\text { DOI: } \\
\text { 10.5530/jyp.2015.3.20 }\end{array}$ \\
\hline
\end{tabular}

of tonic-clonic and complex partial seizures, except absence seizures. ${ }^{3,6}$ The wide pharmacokinetic variability and low toxicity threshold of phenytoin can often result in its intoxication. ${ }^{2,47,8}$ The toxic effects of chronic use may present with wide variety of clinical symptoms and signs. ${ }^{2}$ Here we report a case of phenytoin toxicity in an adolescent female presenting with multiple adverse drug reactions (ADRs).

\section{CASE REPORT}

An eighteen year old female visited the outpatient department of general medicine unit of JSS Medical College and Hospital, Mysore, Karnataka, India. She presented with a history of giddiness and generalised

\footnotetext{
*Address for correspondence:

Dr. Madhan Ramesh, Department of Clinical Pharmacy, JSS Medical College \& Hospital and Department of Pharmacy Practice, JSS College of Pharmacy, JSS University, Mysore-15, Karnataka, India. E-mail : madhanramesh@hotmail.com
} 


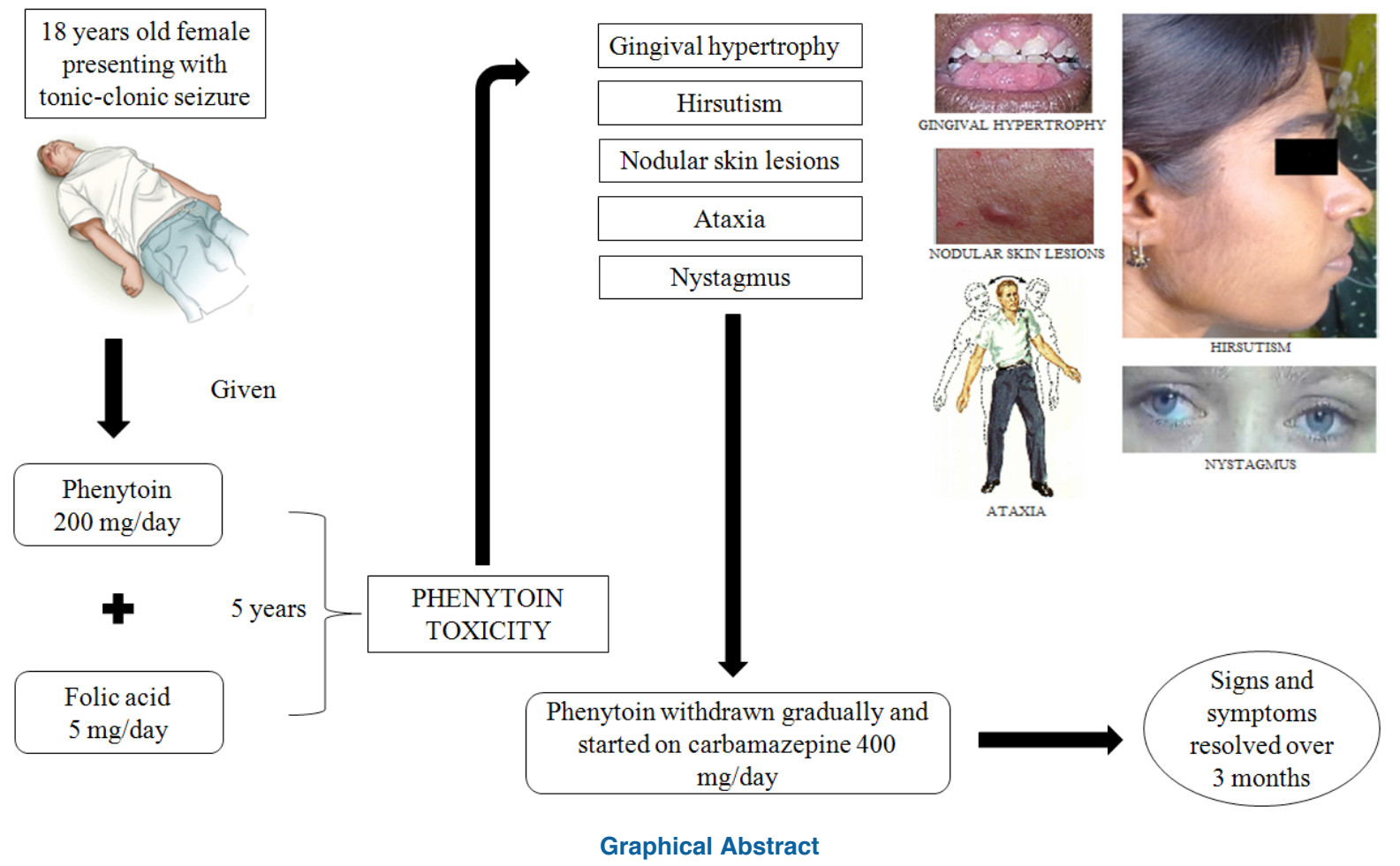

weakness since four days which was sudden in onset. Patient also complained of decreased vision on going into light and there was history of two episodes of vomiting, which was non projectile, non bilious, non blood tinged and contained food particles. On further questioning it was revealed that she had been diagnosed to have generalised tonic-clonic seizures. She was taking tablet phenytoin 200 $\mathrm{mg} /$ day with folic acid $5 \mathrm{mg}$ /day for the past five years. With this treatment she was seizure free and thus was asked to discontinue the medication after three years of treatment initiation. However, due to recurrence of seizures she was advised to restart the medication.

Patient was admitted and on examination, she was found to be moderately built and nourished, conscious oriented to time, place and person. There was gingival hypertrophy with bleeding gums, hirsutism, nodular lesions below the mandible, bilateral horizontal nystagmus, ataxia, impairment in tandem walking and bilateral proximal muscle weakness in the lower limbs (Figure 1). On investigation, her biochemical parameters (Bilirubin total: $0.29 \mathrm{mg} / \mathrm{dL}$, Bilirubin direct: $0.11 \mathrm{mg} / \mathrm{dL}$; Aspartate transaminase: 33 U/L; Alanine transaminase: $28 \mathrm{U} / \mathrm{L}$, Alkaline phosphatase: $329 \mathrm{U} / \mathrm{L}$; Total proteins: $7.88 \mathrm{gm} / \mathrm{dL}$; Albumin: $4.01 \mathrm{gm} /$ $\mathrm{dL}$; Albumin/Globulin ratio: 1.0) were found to be within normal limits. The serum phenytoin levels were found to be $21.6 \mathrm{mcg} / \mathrm{mL}$. Based on the patient's clinical presentations, lab reports and past medication history, diagnosis of phenytoin induced toxicity was considered.
The phenytoin dose was reduced to $100 \mathrm{mg} /$ day and was asked to continue for two weeks with a careful watch for any seizure activity, after which it was discontinued. At the same time, she was started with tablet carbamazepine 400 $\mathrm{mg} /$ day. Within twenty days of drug withdrawal, vomiting and ataxia resolved completely, nystagmus and nodules reduced partially and gingival hypertrophy improved slightly. After another two months, nystagmus and nodular lesions resolved completely, gingival hypertrophy reduced significantly and hirsutism also had decreased.

The Naranjo's criteria and WHO probability scale were applied to determine the causality for suspected ADRs. The causality assessment with both scales revealed that adverse reaction due to phenytoin in this case was probable (Naranjo overall score: 7). The severity of ADRs were evaluated using Modified Hartwig and Siegel, based on which it was categorized as moderate level 4(b) reaction.

\section{DISCUSSION}

Phenytoin has a narrow therapeutic range of 10-20 $\mathrm{mcg} / \mathrm{mL} .{ }^{1,5}$ At plasma concentrations below $10 \mathrm{mcg} /$ $\mathrm{mL}$, elimination follows first order. However, at higher concentrations, including those in the therapeutic range $(10-20 \mathrm{mcg} / \mathrm{mL})$, the metabolic pathway becomes saturated and elimination shifts to zero order. ${ }^{5}$ Half life of phenytoin varies between six and twenty four hours at plasma concentrations less than $10 \mathrm{mcg} / \mathrm{ml}$, but increases 

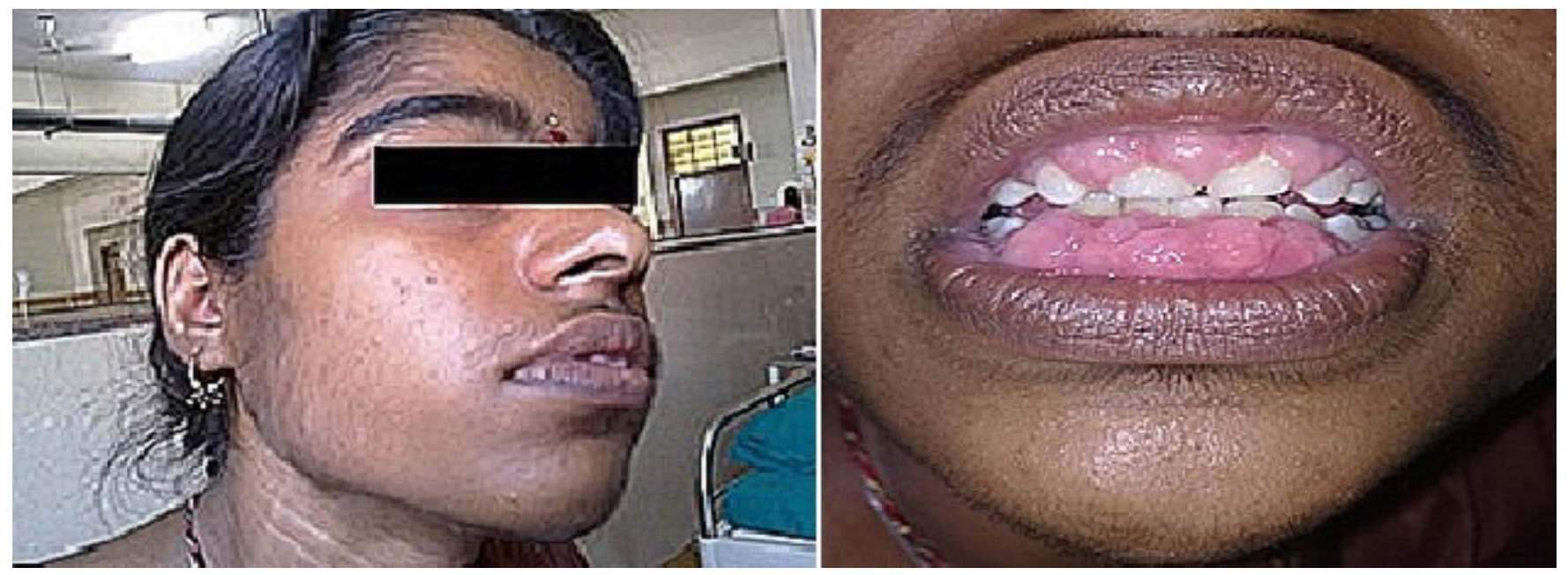

Figure 1: Patient presenting with symptoms of gingival hypertrophy and hirsutism

with higher concentrations. ${ }^{1,3}$ As a result, the plasma concentration rises disproportionally even with small increments in dose. ${ }^{4,5}$ Toxicity generally correlates with the increasing plasma levels. The increased half life due to zero order pharmacokinetics can also result in prolonged duration of toxic symptoms. ${ }^{9}$

The toxic effects seen with chronic treatment are primarily dose related cerebellar-vestibular effects. ${ }^{3}$ It may also cause other central nervous system effects, behavioural changes, increased seizure activity, gastrointestinal symptoms, hirsutism, gingival hyperplasia, osteomalacia and megaloblastic anemia., ${ }^{3,46}$ Our patient presented with ataxia, nystagmus, gingival hypertrophy, nodular skin lesions and hirsutism. Likewise there are reports of phenytoin induced ataxia, nystagmus, ${ }^{2,3}$ gingival hypertrophy, ${ }^{1,10}$ nodular skin lesions ${ }^{10,11}$ and hirsutism ${ }^{10}$ on phenytoin ingestion. Chronic phenytoin ingestion leads to its accumulation in the cerebral cortex, resulting in atrophy of cerebellum, causing ataxia and nystagmus. ${ }^{12}$ Gingival hypertrophy may be attributed to altered collagen metabolism. ${ }^{6}$ Altered metabolism of sex steroid hormones by phenytoin can induce hyperandrogenic symptoms like hirsutism and nodular skin lesions. ${ }^{13}$

The symptoms experienced by the patient in question are understandable in terms of complex pharmacokinetics, narrow therapeutic index and individual variability in metabolism and elimination of phenytoin., ${ }^{2,47}$ Signs of phenytoin toxicity usually manifest at phenytoin levels above $15 \mathrm{mcg} / \mathrm{mL}$. ${ }^{7}$ Serum phenytoin levels were $21.6 \mathrm{mcg} /$ $\mathrm{mL}$ in our patient. These symptoms of toxicity experienced by the patient gradually developed over a period of five years at the usual dose of $200 \mathrm{mg}$ /day. Toxic effects may develop at therapeutic concentrations in some patients. This may be attributed to the unpredictable relationship between serum levels of phenytoin and their side effects. ${ }^{4,8}$ Previous studies point out that phenytoin toxicity may develop over months to year after starting the drug. ${ }^{14}$ This may be due to gradual accumulation of phenytoin over the time period as a result of non linear pharmacokinetics. ${ }^{4}$ These effects can be reversed by withdrawing or reducing the dose of phenytoin. ${ }^{3,8}$

\section{CONCLUSION}

This case report of phenytoin toxicity helps to alert physicians about the toxic manifestations of phenytoin in patients on long term therapy. Long term therapy with phenytoin should be individualised based on the patient's clinical response, plasma drug levels and signs of toxicity. There is also need for regular follow up to assess compliance and response to therapy. Monitoring of serum phenytoin levels and ADRs should be done even when the seizure is under control and especially when there are doubts of early toxic effects. This report also highlights the importance of educating patients and their caregivers about the clinical manifestations of phenytoin toxicity, so that it can be recognized early and treated appropriately.

\section{CONFLICTS OF INTEREST}

The authors declare that they have no conflicts of interest that are directly relevant to the content of the case report.

\section{ACKNOWLEDGEMENT}

The authors would like to thank Principal, JSS College of Pharmacy and JSS University, Mysore for their support and encouragement.

Journal of Young Pharmacists Vol $7 \bullet$ Issue $3 \bullet$ Jul-Sep 2015 


\section{Highlights of Paper}

- Phenytoin causes dose related side effects at normal doses on chronic use.

- Phenytoin induced toxicity leads to ataxia, nystagmus, gingival hypertrophy, nodular skin lesions and hirsutism.

- Monitoring of phenytoin concentration among patients with chronic use will be helpful in prevention, early identification and resolution of phenytoin toxicity.

\section{Author Profile}

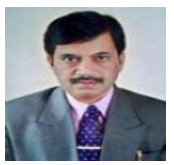

- Dr. Hathur Basavana Gowdappa is a Professor \& Principal of JSS Medical College\& Hospital, Mysore. He is an established and experienced senior physician in General Medicine. Dr Gowdappa is known for his academic excellence, research and administration abilities. He has presented more than 160 papers at various academic forums and has been honoured with eight orations and two lifetime achievement awards.

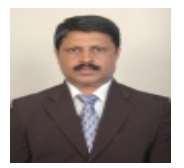

- Dr. Madhan Ramesh, is a Professor \& Head, Department of Pharmacy Practice, JSS College of Pharmacy, is also heading the Clinical Pharmacy Department at JSS Hospital, Mysore. He is a renowned clinical pharmacist and was awarded 'Weary Dunlop Fellow in Clinical Pharmacy' from the Repatriation General Hospital, Adelaide, Australia. He was also awarded with the Roche Products Fellowship Award 1998, Late Smt. VG Yeole Memorial Award 2005 and Late Shri. Ishwar N Hukkeri Award 2010 for his research papers.

\section{REFERENCES}

1. Gosavi DD, Akanksha S, Sanjay N. A case of phenytoin induced gum enlargement. Asian J Pharm Clin Res. 2012; 5(1): 10-1.

2. Thakral A, Shenoy R, Deleu D. Acute visual dysfunction following phenytoin-induced toxicity. Acta Neurol Belg. 2003; 103(4): 218-20.

3. Sharmaa B, Handaa R, Prakasha S, Nagpala K, Gupt P. Phenytoin toxicity presenting as encephalopathy with fatal outcome: a case report. J Neurol Res. 2013; 3(6): 184-6.

4. Solanki MS, Kumar K. Usual erratic phenomenon, dramatic outcome: a case report of phenytoin toxicity. BCP. 2013; 23(1): 81-3.

5. Al-Khulaif AH, Shujaa AS. Phenytoin induced status epilepticus. Neurosciences 2010; 15(2): 131-2.

6. McNamara JO. Drugs effective in the therapy of epilepsies. In: Hardman JG, Limbird LE, Molinoff PB, Ruddon RW, Gilman AG, eds. Goodman \& Gilman's the pharmacological basis of therapeutics. 9 ${ }^{\text {th }}$ ed. New York: McGraw-Hill Professional; 1996. p. 461-86.

7. Lewin S, Rao SDS, Chandrasekhara MK, Vengamma B. Phenytoin toxic encephalopathy. Indian Pediatr. 1993; 30(1): 79-80.

8. Kumar N, Chakraborty A, Suresh SH, Basappaji S, Betdur AL. Phenytoin induced cerebellar atrophy in an epileptic boy. Indian $\mathrm{J}$
Pharmacol. 2013; 45(6): 636-7.

9. Craig S. Phenytoin poisoning. Neurocrit Care. 2005; 3(2): 161-70.

10. Trevisol-Bittencourt PC, Da Silva VR, Molinari MA, Troiano AR. Phenytoin as the first option in female epileptic patients? Arq Neuro-Psiquiatr. 1999; 57(3B): 784-6.

11. Braddock SW, Harrington D, Vose J. Generalized nodular cutaneous pseudolymphoma associated with phenytoin therapy. J Am Acad Dermatol. 1992; 27(2): 337-40.

12. Gupta M, Patidar Y, Khwaja GA, Chowdhury D, Batra A, Dasgupta A. Persistent cerebellar ataxia with cerebellar cognitive affective syndrome due to acute phenytoin intoxication: A case report. Neurol Asia. 2013; 18(1): 107-11.

13. Neraud B, Dewailly D. Drug-induced hyperandrogenism. In: Azziz R, Nestler JE, Dewailly D, eds. Contemporary Endocrinology: Androgen excess disorders in women, polycystic ovarian syndrome and other disorders. $2^{\text {nd }}$ ed. New Jersey: Humana Press Inc; 2006. p. 121-4.

14. Polman AJ, Van Der Werf TS, Tiebosch ATMC, Zijlstra JG. Early onset phenytoin toxicity mimicking a renopulmonary syndrome. Eur Respir J. 1998; 11(2): 501-3. 